\title{
The Place of Local Self-Government in Leprosy Home Administration.
}

\author{
J. Hugh McKean.
}

T EPROSY homes supported entirely or in part by some such organisation as the American Mission to Lepers are confronted with the serious problem of staffing their institutions with an adequate and well trained force. This is due mainly to the fact that funds are limited, and that the number of such institutions requiring financial help are many, and are constantly increasing. As is the case with the Chiengmai Leprosy Home, the superintendents of many such institutions are recruited from the members of the Mission operating in that particular country. Other pressing mission duties make large demands on the time of the superintendent so that many asylums are seriously handicapped by inadequate supervision. We had to meet such a problem at Chiengmai from the very first and found the solution in local self-government. Local self-government as adopted by this institution is patterned after the Siamese form of village government. It has been in operation for more than twenty years, and has given, and still gives satisfaction.

Placing the responsibility on the inmates of the asylum has opened our eyes to the fact that many of them are thoroughly dependable and need only guidance and patience to make them valuable workers. Always before them is the fact that the institution is theirs. As a result, they take pride in their work and are constantly on guard to inspire the same feeling in others who become careless. 
For the purpose of self-government the institution is divided into three distinct groups. Over each group is placed a headman and his assistant, who are responsible for the behaviour of those under their direct charge. A chief headman or mayor elected by them is directly responsible to the management and must answer for the efficient handling of all internal affairs. During recent years, this idea of self-government has been expanded until at the present time practically all of the affairs of this asylum are in the hands of the patients.

A department of Morals and Behaviour functions under the oversight of Christian elders. A sanitary squad of eight men and four women, cares for the sick, gives the semi-weekly injections of chaulmoogra oil and is responsible for the cleanliness of the institution. Homeguards, composed of 27 uniformed men keep order among the more than four hundred inmates and insure protection from outsiders. A court, made up of the chief-headman, the minor headmen, and the elders, tries all minor offences, settles disputes and imposes penalties. The management sits with the court only in an advisory capacity. A labour organisation has charge of all work of the institution. Each kind of work is under the supervision of a skilled workman trained in the asylum. In this labour group are to be found clerks, storekeepers, masons, carpenters, blacksmiths, sawyers, tailors, barbers, painters, \&cc. Practically every patient is a worker. Only the incapacitated are exempt. Each individual is assigned work according to his physical strength and ability.

In an institution of four hundred patients, the variety of work is comparable to that of any other village of like size. More than 140 buildings fronted with fences provides ample work for a score of men. The numerous roads, with flowers and strips of lawn, give work to many who are unable to do heavy labour. We believe in work as an integral part of treatment. It keeps patients physically fit, and it is our experience that those who work are able to take maximum injections of chaulmoogra oil with very little discomfort. Best of all our patients believe in the efficacy of work which makes the assignment of tasks a comparatively easy matter.

The advantages resulting from the above-mentioned scheme of self-government are many, only the most apparent of which are mentioned.

(1) It relieves the management of an enormous amount of detailed oversight of a type for which it is hardly fitted.

(2) Under an enterprising and wise headman the intimate affairs of their daily lives runs smoothly. 
(3) It brings contentment and fosters a feeling of responsibility towards, and pride in, an efficient management.

(4) It changes their status from " outcast " to " Citizen." The inmates of this institution are encouraged in all their attempts to assume responsibility. It is a task requiring considerable patience and self-effacement on the part of the management, but one which brings in rich rewards to both the inmates and those who have the work in hand. 